\title{
Androgen deprivation therapy for prostate cancer: long-term safety and patient outcomes
}

\author{
This article was published in the following Dove Press journal: \\ Patient Related Outcome Measures \\ 5 July 2014 \\ Number of times this article has been viewed
}

\author{
Hamed Ahmadi \\ Siamak Daneshmand \\ Institute of Urology, University of \\ Southern California, Los Angeles, \\ CA, USA
}

Correspondence: Siamak Daneshmand USC Institute of Urology, University of Southern California/Norris Comprehensive Cancer Center, I44I Eastlake Avenue, Suite 7416 Los Angeles, CA, USA 90089-22I I

Tel +I 3238653709

$\mathrm{Fax}+\mathrm{I} 3238650120$

Email daneshma@med.usc.edu

\begin{abstract}
Androgen deprivation therapy (ADT) constitutes the first-line treatment for patients with locally advanced tumors, recurrent or metastatic disease. Given its widespread use, clinicians should be familiar with common side effects of this treatment. This review focuses on common side effects of ADT and available treatment options to control the side effects. Also, it briefly compares continuous ADT with other therapeutic approaches for androgen deprivation in prostate cancer patients. Similar to hormonal medications, newer non-hormonal therapeutic options including gabapentin and acupuncture have at best moderate effect in controlling hot flashes in patients on ADT. Supervised and/or home exercise programs significantly improve ADT-related fatigue, metabolic/cardiovascular side effects, and cognitive dysfunction. Denosumab, a human monoclonal antibody against RANK-L, is more effective than bisphosphonates in preventing skeletal-related events in patients with metastatic or castrate-resistant prostate cancer and unlike bisphosphonates, it can also reduce the risk of vertebral fractures in men receiving ADT for non-metastatic prostate cancer. Toremifene, a selective estrogen receptor inhibitor, has dual beneficial effects on ADT-related osteoporosis and metabolic dysfunction. Metformin coupled with lifestyle modification is also a well-tolerated treatment for metabolic changes during ADT. While producing similar oncological outcomes, intermittent ADT is associated with higher quality of life in patients under ADT by improving bone health, less metabolic and hematologic complications, and fewer hot flashes and sexual dysfunction events.
\end{abstract}

Keywords: prostate cancer, androgen deprivation therapy, adverse effects, therapy

\section{Introduction}

Androgen deprivation therapy (ADT) is one of the most common forms of treatment for advanced prostate cancer (PCa). The benefits of ADT as the primary treatment or in combination with other therapies such as prostatectomy or radiotherapy are wellestablished in men with locally advanced PCa. ADT can normalize serum prostate specific antigen in over $90 \%$ of patients and results in sizable tumor response in $80 \%$ to $90 \%$. This treatment can be done either with bilateral orchiectomy (surgical castration) or medical castration (using either a gonadotropin releasing hormone [GnRH] agonist or a GnRH antagonist). Bilateral orchiectomy is still considered the standard hormonal treatment for metastatic PCa in some countries. However, the most widely used approach is continuous treatment with GnRH agonists. The introduction of ADT, especially in asymptomatic men, results in undesirable changes in different health-related quality of life (HRQOL) domains including vitality, physical function, bodily pain, and role-physical domains. In fact, patients receiving primary ADT show more significant HRQOL declines in both general and PCa-specific 
HRQOL compared to those receiving combination ADT and local therapy. ${ }^{1}$ Given the widespread use of ADT, it is imperative that clinicians understand the side effects in order to limit treatment-related morbidity. There are numerous well recognized adverse effects of ADT which include vasomotor flushing, loss of libido and impotence, fatigue, gynecomastia, anemia, and osteoporosis. Obesity, insulin resistance, and dyslipidemia are more recently described metabolic complications. Long-term use of ADT also has deleterious effects on cardiovascular health. ${ }^{2}$ This review focuses on the long-term safety profile of ADT and available treatment options to minimize the side effects and improve patients' quality of life.

\section{Literature search}

A PubMed database search was conducted to select published prospective clinical studies including randomized and nonrandomized clinical trials, meta-analysis, and review articles with regards to therapeutic options for ADT-related side effects from 2000 to 2014.

\section{Side effects}

\section{Vasomotor flushing}

Hot flashes are one of the most bothersome side effects of ADT, affecting up to $80 \%$ of men on this treatment. ${ }^{3}$ Almost $30 \%$ of patients consider hot flashes the most distressing side effect of ADT and more frequent or severe hot flashes are associated with greater distress. Approximately half of patients still experience hot flashes even after 5 years of ADT. ${ }^{3}$ Low testosterone levels interrupt the negative feedback mechanism in hypothalamic noradrenaline production and reset the hypothalamic thermoregulatory center which results in vasomotor flushing.

A practical initial approach would be behavioral modifications such as use of a fan, lowering room temperature, use of loose fitting clothing, and cold drinks which have minimal adverse effects and may make symptoms tolerable. ${ }^{4}$ Currently available therapeutic options can be divided into hormonal and non-hormonal treatments: Megestrol acetate and medroxyprogesterone acetate $(20 \mathrm{mg}$ once or twice a day) as well as diethylstilbestrol ( $1 \mathrm{mg} /$ day) are among progestational agents that can significantly reduce the frequency and severity of hot flashes between 1 to 3 months after initiation of therapy. ${ }^{5}$ Cyproterone acetate $(100 \mathrm{mg} /$ day $)$ is a steroidal antiandrogen that can also cause remarkable reduction in hot flashes comparable to the effect of progestational agents. Given the interference between cyproterone acetate and hormonal therapy, progestational agents are currently the gold standard hormonal therapy for hot flashes. ${ }^{6}$ Breast enlargement and/or tenderness caused by estrogen agents and occasional rise in prostate-specific antigen levels by progestational hormones are some of the common side effects of hormonal agents. ${ }^{5}$

Among non-hormonal treatments, selective serotonin and serotonin norepinephrine reuptake inhibitors such as paroxetine, venlafaxine, sertraline, and fluvoxamine modulate central dopaminergic activity and cause moderate decrease in hot flashes. Venlafaxine ( $75 \mathrm{mg}$ daily) is less effective than hormonal therapies and common side effects such as dry mouth, nausea, weight gain, night sweats, and headache as well as its drug interaction limit their daily usage. ${ }^{6}$ Gabapentin, an antiseizure agent, also appears to provide moderate efficacy for long-term treatment of hot flashes with the initial dose of $300 \mathrm{mg}$ daily which is increased by increments of $300 \mathrm{mg}$ in order to achieve a dose of $900 \mathrm{mg}$ divided in three equal doses a day. Men, who are suffering mainly from night sweats, can use a bedtime dose of 100-300 mg with further titration of the bedtime dose to $900 \mathrm{mg} /$ day. Common side-effects include leukocytopenia with flu-like symptoms, somnolence, depressed mood, gastrointestinal symptoms, and muscle and joint pain, which are usually well-tolerated. ${ }^{7}$ Studies have also shown that acupuncture for 3 months (twice a week for the first 2 weeks and then once a week for 8 to 10 weeks) can have a moderate, longlasting reduction in hot flashes frequency. The mechanism of action is not clear but it seems to act through its effect on serotonin, beta-endorphin, and calcitonin gene-related peptide activity. Common side effects such as hematoma at the insertion site, fatigue, and distress usually occur early and are insignificant. There is no specific late side effect reported in the literature. ${ }^{8}$ Pregabalin, a gabapentin analog, has also been studied for the treatment of hot flashes in women and showed a significant reduction in hot flashes, to a similar degree as had been observed with gabapentin. Randomized clinical trials, however, have not been performed to evaluate the utility of pregabalin for treating ADT-associated hot flashes. Clonidine in the form of a transdermal patch has not proven to be effective for hot flashes in men ${ }^{9}$ and concerns about the increased risk of PCa with vitamin $\mathrm{E}$ has made it a less desirable treatment option. ${ }^{10}$

\section{Fatigue}

Approximately $43 \%$ of men receiving long-term ADT suffer from fatigue ${ }^{3}$ and it is a major concern for quality of life in men with less aggressive disease. Increased fat mass along with the loss of lean muscle mass in combination 
with pain and depression is probably the main underlying mechanism. Exercise and muscle strengthening programs are appropriate interventions to reduce the frequency and severity of fatigue in these patients by improving muscular strength, cardiorespiratory fitness, functional task performance, and lean body mass. Supervised clinical exercise composed of resistance training with or without aerobic training (cardiovascular exercises including cycling and walking/jogging at $65 \%-80 \%$ of maximum heart rate for 15-20 minutes) two to three times a week for 3 months or a home exercise program (light resistance training, walking, stretching) three to five times a week coupled with group training once a week for 4 months remarkably reduces fatigue. ${ }^{11,12}$ Two ongoing trials looking at the effect of walking exercise and heavy strength training programs on body composition and fatigue will provide more evidence in this regard. ${ }^{13,14}$

\section{Sexual dysfunction}

Sexual dysfunction happens in up to $91 \%$ of men on ADT and it deteriorates during the course of treatment. ${ }^{15}$ Suppressed testosterone levels cause decreased nitric oxide levels and loss of intercavernosal pressure and lead to a significant decrease in libido and erectile function. ${ }^{16}$ Qualitative studies show complete loss of libido, sexual fantasies, and erotic dreams, all of which could lead to marital erosion. ${ }^{17,18} \mathrm{~A}$ consensus report from the multidisciplinary ADT Survivorship Working Group provides both evidence-based and consensus-based management strategies for sexual side effects of ADT which briefly include: educational sessions for couples about the side effects of treatment prior to the start of ADT; $;^{18}$ parenteral estrogen therapy such as gel or transdermal estradiol patches to preserve libido; and individualized psychological intervention such as sexual-therapy techniques to provoke sexual fantasies, mindfulness techniques, and cognitive reframing of the sexual experience. ${ }^{19}$ Phosphodiesterase inhibitors may be less successful in this situation compared to other etiologies and patients should be aware of the importance of physical and mental sexual arousal to maximize the effect of these drugs. ${ }^{19}$ Intracorporeal injection, vacuum erection devices, or penile prosthesis are among other treatment options. Sexual aids such as intracavernosal injections, vibrators, or masturbatory or penetrative aids may be effective in patients who have difficulty attaining orgasm. Perineal/perianal stimulation and mental preparation for an altered masculine role may also be advantageous. ${ }^{19}$ General muscle strengthening exercises can also improve sexual function in some patients. ${ }^{11}$

\section{Skeletal-related events}

Long-term ADT can also cause loss of bone mineral density (BMD) which is mostly asymptomatic but up to $20 \%$ of men under ADT may eventually experience bone fracture. ${ }^{20}$ Monitoring bone health and bone loss preventive measures are highly recommended in patients on long term ADT as the risk of loss of BMD and bone fracture is directly associated with the length of ADT treatment. Baseline BMD measurement using dual X-ray absorptiometry before starting ADT and regular BMD measurements based on initial T-score, lifestyle modifications such as increased exercise, calcium $(1,500 \mathrm{mg})$ and vitamin D (800 IU) supplementation, smoking cessation, decreased alcohol consumption, and weight loss are among the suggested monitoring and preventive measures. ${ }^{21}$ Bisphosphonates clearly prevent bone loss and increase BMD in PCa patients on long-term ADT and intravenous zolendronic acid also prevents fractures in men with metastatic and castrate-resistant PCa. Clinical trials have failed to show any fracture-prevention effect of bisphosphonates in men with non-metastatic PCa on ADT. Denosumab, a human monoclonal antibody against RANK-L, however, has been shown to reduce the risk of vertebral fractures in men receiving ADT for non-metastatic PCa. Denosumab has also been shown to be superior to zoledronic acid in preventing skeletal-related events in patients with metastatic or castrate-resistant $\mathrm{PCa} .{ }^{21}$ However, neither of these drugs have been shown to prevent bone metastasis in non-metastatic $\mathrm{PCa} .{ }^{22}$ Raloxifene and toremifene citrate, selective estrogen receptor modulators, have shown encouraging results in improving total hip, lumbar spine, and femoral neck BMD in men on ADT. ${ }^{21}$

\section{Anemia}

Although ADT leads to anemia in as many as $90 \%$ of patients, more than $70 \%$ of patients are unaware of this side effect before the start of the treatment. ${ }^{23}$ Treatment is only required for symptomatic patients with severe anemia and the majority of patients with mild to moderate anemia do not need any intervention. Individualized treatment strategy with respect to the risk-benefit ratio of each treatment such as erythropoiesis-stimulating agents (ESAs) is usually considered in this situation: malnutrition and nutrient deficiencies such as iron and vitamin B12/folate should be appropriately substituted by oral or parenteral supplementations. Regular blood transfusions may be the only effective treatment option in some patients with severe anemia, metastatic cancer, and limited bone marrow reserve. For other anemic patients, there is strong evidence of the favorable hematological effect of ESA. However, there are some concerns regarding increased 
Table I Common side effects of androgen deprivation therapy and recommended treatment options

\begin{tabular}{|c|c|c|}
\hline Side effects & Prevalence & Recommended treatment(s) \\
\hline Hot flashes & Up to $80 \%$ & $\begin{array}{l}\text { - Behavioral modification (fan, lowering room temperature, loose fitting clothes, cold drinks) } \\
\text { Hormonal medications } \\
\text { - Progesterone agents } \\
\circ \text { Megestrol acetate ( } 20 \mathrm{mg} \text { QD or BID) } \\
\circ \text { Medroxyprogesterone acetate ( } 20 \mathrm{mg} \text { QD or BID) } \\
\text { - Estrogen agents } \\
{ }^{\circ} \text { Diethylstilbestrol (I mg/day) } \\
\text { Non-hormonal medications } \\
\text { - Selective serotonin reuptake inhibitors } \\
{ }^{\circ} \text { Paroxetine ( } 10 \mathrm{mg} / \text { day) }{ }^{42} \\
{ }^{\circ} \text { Fluvoxamine ( } 25 \mathrm{mg} / \text { day) }{ }^{43} \\
\text { - Selective serotonin norepinephrine reuptake inhibitors } \\
{ }^{\circ} \text { Venlafaxine ( } 75 \mathrm{mg} / \text { day) } \\
\circ \text { Gabapentin ( } 300 \mathrm{mg} \text { daily titrated to } 300 \mathrm{mg} \text { TID) } \\
\text { Other treatments } \\
\circ \text { Acupuncture (twice a week for the first } 2 \text { weeks and then once a week for } 8 \text { to } 10 \text { weeks) }\end{array}$ \\
\hline Fatigue & $43 \%$ & $\begin{array}{l}\text { - Supervised clinical exercise } \\
\text { - Resistance training } \pm \text { aerobic training } 2-3 \text { times/week; } 12 \text { weeks total } \\
\text { - Home exercise program (light resistance training, walking, stretching) 3-4 times/week and group } \\
\text { training once a week; } 16 \text { weeks total }\end{array}$ \\
\hline Sexual dysfunction & $80 \%$ & $\begin{array}{l}\text { - Educational sessions for couples about the sexual side effects of treatment before the start of ADT } \\
\text { - Parenteral estrogen therapy } \\
{ }^{\circ} \text { Gel } \\
\circ \text { Transdermal estradiol patch } \\
\text { - Individualized psychological intervention } \\
\circ \text { Sexual therapy techniques } \\
\text { - Erectile dysfunction } \\
{ }^{\circ} \text { Phosphodiesterase inhibitors } \\
\circ \text { Intracorporeal injection } \\
\circ \text { Vacuum erection devices } \\
\circ \text { Penile prosthesis } \\
\text { - Difficulty obtaining orgasm } \\
\circ \text { Intracavernosal injections } \\
\circ \text { Vibrators } \\
\circ \text { Masturbatory or penetrative aids } \\
\circ \text { Perineal/perianal stimulation } \\
\text { - Muscle strengthening exercise }\end{array}$ \\
\hline Skeletal-related events & Up to $20 \%$ & 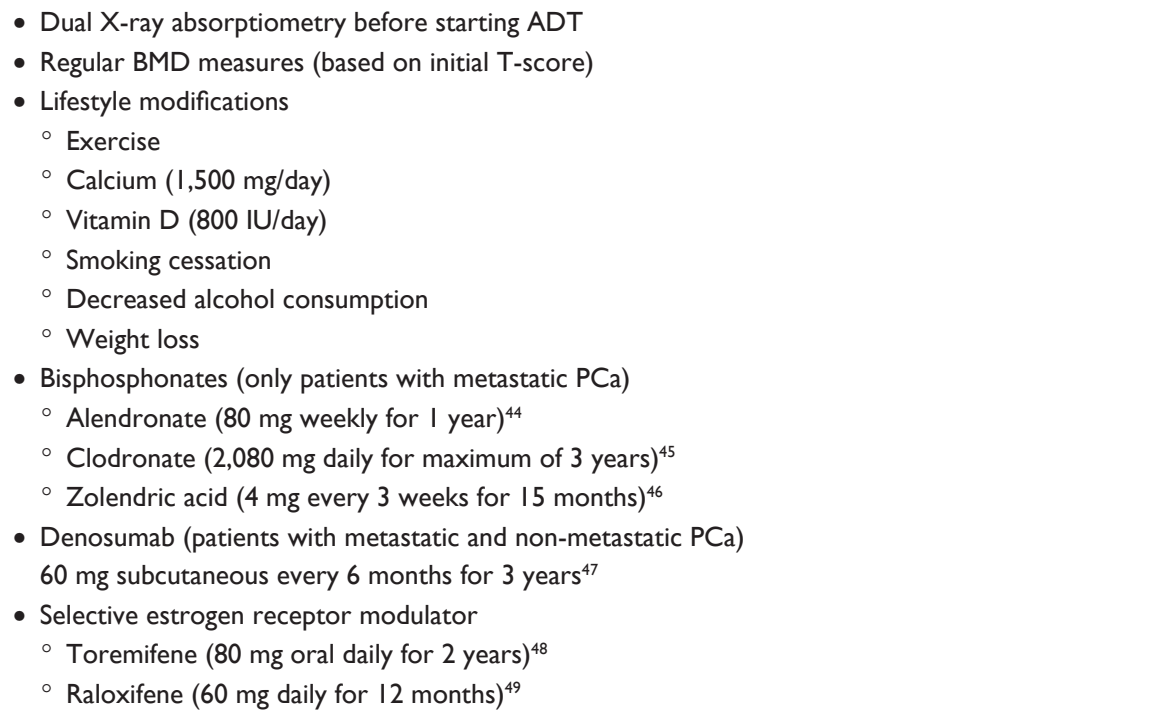 \\
\hline
\end{tabular}


Table I (Continued)

\begin{tabular}{|c|c|c|}
\hline Side effects & Prevalence & Recommended treatment(s) \\
\hline Anemia & $90 \%$ & $\begin{array}{l}\text { Only indicated in severe anemia } \\
\text { - Substitution of malnutrition and nutrient deficiencies such as iron and vitamin BI2 } \\
\text { - Erythropoiesis-stimulating agents } \\
\text { Darbepoetin } \alpha 300-1,000 \mu \mathrm{g} \text { (changes based on the hemoglobin response) every } 4 \text { weeks for } \\
6 \text { months }{ }^{50} \\
\text { - Regular blood transfusion }\end{array}$ \\
\hline Metabolic/cardiovascular & $14 \%-70 \%^{3}$ & $\begin{array}{l}\text { - Screening protocol, ie, annual lipid profile } \\
\text { - Lifestyle modifications } \\
\text { - Smoking cessation } \\
\text { - Weight loss } \\
\text { - Regular exercise } \\
\text { - Secondary preventive measures } \\
\text { - Glucose-lowering therapy } \\
\text { - Statin therapy } \\
\text { - Antihypertensive therapy } \\
\text { - Aspirin (unless contraindicated) } \\
\text { Metformin ( } 850 \text { mg daily for } 2 \text { weeks and } 850 \text { mg twice a day afterwards) plus lifestyle } \\
\text { modifications (ie, dietary advice and regular aerobic exercise) for } 6 \text { months } \\
\text { - Tupernifene ( } 80 \text { mg daily) for I year } \\
\text { - Home/group exercise programs }\end{array}$ \\
\hline Cognitive dysfunction & $45 \%^{31}$ & - Combined resistance/aerobic exercise program for 3 months \\
\hline
\end{tabular}

Abbreviations: ADT, androgen deprivation therapy; BID, twice a day; BMD, bone mineral density; PCa, prostate cancer; QD, once a day; TID, three times a day.

risk of thromboembolic events following this treatment and also the impact of ESAs on overall survival in PCa patients. Clinical benefit of low dose dexamethasone is not wellestablished. $^{24}$

\section{Metabolic and cardiovascular effects}

ADT increases obesity, decreases insulin sensitivity, and adversely alters lipid profiles. It may be associated with a greater incidence of diabetes and cardiovascular disease. ${ }^{25}$ It is, however, still not clear whether the type of ADT or preexisting cardiovascular morbidity determine the risk of a cardiovascular event in this population. ${ }^{26}$ Since the majority of men with PCa under ADT are elderly and have known cardiovascular disease or diabetes mellitus or the risk factors to develop them, preventive strategies including lifestyle modifications (smoking cessation, weight loss if they are overweight at baseline or become overweight, and regular exercise) and screening protocols such as yearly lipid profiles are recommended. Secondary preventative measures such as glucose-lowering therapy, statin therapy, antihypertensive therapy, and aspirin (unless contraindicated) are also recommended for men with existing cardiovascular disease or in men who recently developed cardiovascular disease from ADT. ${ }^{27}$ Metformin ( $850 \mathrm{mg}$ daily for 2 weeks and $850 \mathrm{mg}$ twice a day afterwards) coupled with lifestyle modifications such as dietary advice and regular aerobic exercise for 6 months is a well-tolerated treatment option that causes significant reduction in abdominal girth, weight, and systolic blood pressure. ${ }^{28}$ Toremifene acetate also improves lipid profile with significant decrement in total and lowdensity lipoprotein cholesterol and triglyceride. ${ }^{29} \mathrm{~A} 3$-month supervised exercise program involving aerobic and resistance exercise can preserve appendicular lean mass, prevent gains in whole body and trunk fat mass, improve cardiovascular fitness, and decrease total-cholesterol-to-high-densitylipoprotein-cholesterol ratio. ${ }^{30}$ Home and/or group exercise program also improves systolic and diastolic blood pressure and waist and neck girth. ${ }^{11}$

\section{Cognitive dysfunction}

The true incidence of cognitive dysfunction is unclear. Some studies report decline in memory and executive functioning $^{31}$ while others have failed to show any adverse effects. ${ }^{32}$ Advanced age, disease stage, and comorbidities may all contribute to cognitive disturbances in patients on longterm ADT. So far, there is no definite preventive or curative treatment for cognitive impairment in this population. Oral estradiol does not improve cognitive parameters in patients under ADT. ${ }^{5}$ It also accompanies serious side effects such as thromboembolic events and the timing of the treatment also is 
not well established. A 12-week combined resistance/aerobic exercise program also seems to be an efficient countermeasure for cognitive impairments in patients on ADT. ${ }^{30,33}$

\section{Urinary function}

ADT can decrease prostate volume, decrease lower urinary tract symptoms, and improve quality of life in patients with PCa who have moderate to severe voiding dysfunction. ${ }^{34}$ Also, ADT is recommended in some patients to decrease prostate volume, downstage the disease and also prevent urinary retention prior to radiation therapy with intent to cure. ${ }^{35}$ Although ADT has been linked with some metrics of urinary incontinence, urinary incontinence is mostly seen in older patients, and intuitively, it seems to be more associated with age-related pelvic floor muscle weakening rather than ADT.

\section{Alternative androgen deprivation therapies}

Intermittent androgen deprivation (IAD) alternates androgen blockade with treatment cessation to allow hormonal recovery between treatment cycles and it seems, mainly in the setting of metastatic PCa, that IAD can produce oncologic results similar to continuous $\mathrm{ADT} .{ }^{36}$ IAD can potentially improve tolerability and quality of life in patients under ADT. Patients on IAD have improved bone health, less metabolic and hematologic complications, fewer hot flashes, as well as improved sexual function. ${ }^{37}$ The risk of cardiovascular events also seems to be similar between IAD and continuous ADT. ${ }^{38}$ Collectively, evidence from a Phase III randomized controlled trial shows that the quality of life benefit of IAD appears to be modest at best and it is likely influenced by the duration of the off-treatment periods and by the rate of testosterone recovery. ${ }^{39}$

Non-steroidal anti-androgens competitively inhibit the binding of androgens to the androgen receptor and maintain the serum testosterone levels. Bicalutamide is the preferred drug of this group given its more favorable safety profile. Bicalutamide monotherapy (150 mg daily) is an acceptable option for primary or adjuvant treatment in younger, sexually active patients with locally advanced disease and in highly selected, well-informed patients with metastatic disease. ${ }^{40}$ It can also preserve BMD, muscle strength, and HRQOL in osteoporotic men with non-metastatic locally advanced PCa. ${ }^{41}$ The most important side effect of bicalutamide is gynecomastia and breast pain, which occurs in $70 \%$ to $80 \%$ of patients and leads to a $16.4 \%$ treatment cessation. $^{40}$

\section{Conclusion}

Despite the well-documented oncological benefits of ADT, the treatment should be individualized with regard to the optimal length of ADT and the risk-benefit ratio of each treatment. Since some of the ADT-related side effects may occur over years of therapy and have life-threatening consequences, both specialists and primary care providers need to be aware of and discuss the potential side effects of ADT with patients. It seems that progestational agents and gabapentin are preferable medical treatments and can help decreasing the severity and frequency of hot flashes with a more desirable safety profile. However, there is still no curative treatment available for this significant side effect and hot flashes should be discussed with patients prior to initiating ADT. Exercise programs are effective interventions for fatigue and cognitive dysfunction. Along with simple interventions such as diet modification, they can also have significant beneficial effects on cardiovascular/metabolic events. Denosumab, coupled with life style modification, can effectively prevent BMD loss and fracture in either a nonmetastatic or metastatic PCa setting. Aggressive management of hyperlipidemia also decreases the risk of cardiovascular disease. Patients' comorbidities and functional status are essential factors to be considered prior to initiation of ADT. It is wise to consider active surveillance in elderly patients with biochemical recurrences, particularly those with pre-existing cardiovascular disease, with close monitoring of prostate specific antigen doubling time; ADT should be avoided in this population given the side effect profile and lack of known benefit.

\section{Disclosure}

The authors report no conflicts of interest in this work.

\section{References}

1. Resnick MJ, Penson DF. Quality of life with advanced metastatic prostate cancer. Urol Clin North Am. 2012;39(4):505-515.

2. Ahmadi H, Daneshmand S. Androgen deprivation therapy: evidencebased management of side effects. BJU Int. 2013;111(4):543-548.

3. Walker LM, Tran S, Robinson JW. Luteinizing hormone - releasing hormone agonists: a quick reference for prevalence rates of potential adverse effects. Clin Genitourin Cancer. 2013;11(4):375-384.

4. Jones JM, Kohli M, Loprinzi CL. Androgen deprivation therapyassociated vasomotor symptoms. Asian J Androl. 2012;14(2):193-197.

5. Mohile SG, Mustian K, Bylow K, Hall W, Dale W. Management of complications of androgen deprivation therapy in the older man. Crit Rev Oncol Hematol. 2009;70(3):235-255.

6. Irani J, Salomon L, Oba R, Bouchard P, Mottet N. Efficacy of venlafaxine, medroxyprogesterone acetate, and cyproterone acetate for the treatment of vasomotor hot flushes in men taking gonadotropin-releasing hormone analogues for prostate cancer: a double-blind, randomised trial. Lancet Oncol. 2010;11(2):147-154.

7. Moraska AR, Atherton PJ, Szydlo DW, et al. Gabapentin for the management of hot flashes in prostate cancer survivors: a longitudinal continuation Study-NCCTG Trial N00CB. J Support Oncol. 2010;8(3):128-132. 
8. Lee MS, Kim KH, Shin BC, Choi SM, Ernst E. Acupuncture for treating hot flushes in men with prostate cancer: a systematic review. Support Care Cancer. 2009;17(7):763-770.

9. Loprinzi CL, Goldberg RM, O'Fallon JR, et al. Transdermal clonidine for ameliorating post-orchiectomy hot flashes. J Urol. 1994;151(3): 634-636.

10. Klein EA, Thompson IM Jr, Tangen CM, et al. Vitamin E and the risk of prostate cancer: the Selenium and Vitamin E Cancer Prevention Trial (SELECT). JAMA. 2011;306(14):1549-1556.

11. Baumann FT, Zopf EM, Bloch W. Clinical exercise interventions in prostate cancer patients - a systematic review of randomized controlled trials. Support Care Cancer. 2012;20(2):221-233.

12. Gardner JR, Livingston PM, Fraser SF. Effects of exercise on treatmentrelated adverse effects for patients with prostate cancer receiving androgen-deprivation therapy: a systematic review. $J$ Clin Oncol. 2014;32(4):335-346

13. Thorsen L, Nilsen TS, Raastad T, Courneya KS, Skovlund E, Fosså SD. A randomized controlled trial on the effectiveness of strength training on clinical and muscle cellular outcomes in patients with prostate cancer during androgen deprivation therapy: rationale and design. $B M C$ Cancer. 2012;12:123.

14. Lee CE, Kilgour AR, Lau YK. Efficacy of walking exercise in promoting cognitive-psychosocial functions in men with prostate cancer receiving androgen deprivation therapy. BMC Cancer. 2012;12:324.

15. Ng E, Woo HH, Turner S, Leong E, Jackson M, Spry N. The influence of testosterone suppression and recovery on sexual function in men with prostate cancer: observations from a prospective study in men undergoing intermittent androgen suppression. $J$ Urol. 2012;187(6):2162-2166.

16. Guay AT. Testosterone and erectile physiology. Aging Male. 2006;9(4): 201-206.

17. Navon L, Morag A. Advanced prostate cancer patients' ways of coping with the hormonal therapy's effect on body, sexuality, and spousal ties. Qual Health Res. 2003;13(10):1378-1392.

18. Walker LM, Hampton AJ, Wassersug RJ, Thomas BC, Robinson JW. Androgen Deprivation Therapy and maintenance of intimacy: a randomized controlled pilot study of an educational intervention for patients and their partners. Contemp Clin Trials. 2013;34(2):227-231.

19. Elliott S, Latini DM, Walker LM, Wassersug R, Robinson JW; ADT Survivorship Working Group. Androgen deprivation therapy for prostate cancer: recommendations to improve patient and partner quality of life. J Sex Med. 2010;7(9):2996-3010.

20. Shahinian VB, Kuo YF, Freeman JL, Goodwin JS. Risk of the "androgen deprivation syndrome" in men receiving androgen deprivation for prostate cancer. Arch Intern Med. 2006;166(4):465-471.

21. Schulman C, Irani J, Aapro M. Improving the management of patients with prostate cancer receiving long-term androgen deprivation therapy. BJU Int. 2012;109 Suppl 6:13-21.

22. Saylor PJ. Bone targeted therapies for the prevention of skeletal morbidity in men with prostate cancer. Asian J Androl. 2014;16(3):341-347.

23. Walker LM, Tran S, Wassersug RJ, Thomas B, Robinson JW. Patients and partners lack knowledge of androgen deprivation therapy side effects. Urol Oncol. 2013;31(7):1098-1105.

24. Grossmann M, Zajac JD. Hematological changes during androgen deprivation therapy. Asian J Androl. 2012;14(2):187-192.

25. Saylor PJ, Smith MR. Metabolic complications of androgen deprivation therapy for prostate cancer. J Urol. 2013;189(Suppl 1):S34-S42; discussion S43-S34.

26. Albertsen PC, Klotz L, Tombal B, Grady J, Olesen TK, Nilsson J. Cardiovascular morbidity associated with gonadotropin releasing hormone agonists and an antagonist. Eur Urol. 2014;65(3):565-573.

27. Levine GN, D'Amico AV, Berger P, et al; American Heart Association Council on Clinical Cardiology and Council on Epidemiology and Prevention, the American Cancer Society, and the American Urological Association. Androgen-deprivation therapy in prostate cancer and cardiovascular risk: a science advisory from the American Heart Association, American Cancer Society, and American Urological Association: endorsed by the American Society for Radiation Oncology. Circulation. 2010;121(6):833-840.
28. Nobes JP, Langley SE, Klopper T, Russell-Jones D, Laing RW. A prospective, randomized pilot study evaluating the effects of metformin and lifestyle intervention on patients with prostate cancer receiving androgen deprivation therapy. BJU Int. 2011;109(10):1495-1502.

29. Smith MR, Malkowicz SB, Chu F, et al. Toremifene improves lipid profiles in men receiving androgen-deprivation therapy for prostate cancer: interim analysis of a multicenter phase III study. J Clin Oncol. 2008;26(11):1824-1829.

30. Cormie P, Galvao DA, Spry N, et al. Can supervised exercise prevent treatment toxicity in prostate cancer patients initiating androgen deprivation therapy: a randomised controlled trial. BJU Int. Epub 2014 Jan 27.

31. Mohile SG, Lacy M, Rodin M, et al. Cognitive effects of androgen deprivation therapy in an older cohort of men with prostate cancer. Crit Rev Oncol Hematol. 2010;75(2):152-159.

32. Alibhai SM, Breunis H, Timilshina N, et al. Impact of androgendeprivation therapy on cognitive function in men with nonmetastatic prostate cancer. J Clin Oncol. 2010;28(34):5030-5037.

33. Galvão DA, Taaffe DR, Spry N, Joseph D, Newton RU. Combined resistance and aerobic exercise program reverses muscle loss in men undergoing androgen suppression therapy for prostate cancer without bone metastases: a randomized controlled trial. J Clin Oncol. 2009;28(2):340-347.

34. Axcrona K, Aaltomaa S, da Silva CM, et al. Androgen deprivation therapy for volume reduction, lower urinary tract symptom relief and quality of life improvement in patients with prostate cancer: degarelix vs goserelin plus bicalutamide. BJU Int. 2012;110(11):1721-1728.

35. Tewari A. Prostate Cancer: A Comprehensive Perspective: A Comprehensive Perspective. Berlin: Springer; 2013.

36. Niraula S, Le LW, Tannock IF. Treatment of prostate cancer with intermittent versus continuous androgen deprivation: a systematic review of randomized trials. J Clin Oncol. 2013;31(16):2029-2036.

37. Heidenreich A, Bastian PJ, Bellmunt J, et al. EAU guidelines on prostate cancer. Part II: Treatment of advanced, relapsing, and castration-resistant prostate cancer. Eur Urol. 2014;65(2):467-479.

38. Hussain M, Tangen CM, Berry DL, et al. Intermittent versus continuous androgen deprivation in prostate cancer. $N$ Engl J Med. 2013;368(14): 1314-1325.

39. Sciarra A, Abrahamsson PA, Brausi M, et al. Intermittent androgendeprivation therapy in prostate cancer: a critical review focused on phase 3 trials. Eur Urol. 2013;64(5):722-730.

40. Wirth MP, Hakenberg OW, Froehner M. Antiandrogens in the treatment of prostate cancer. Eur Urol. 2007;51(2):306-313; discussion 314.

41. Wadhwa VK, Weston R, Parr NJ. Bicalutamide monotherapy preserves bone mineral density, muscle strength and has significant health-related quality of life benefits for osteoporotic men with prostate cancer. $B J U$ Int. 2010;107(12): 1923-1929.

42. Naoe M, Ogawa Y, Shichijo T, Fuji K, Fukagai T, Yoshida H. Pilot evaluation of selective serotonin reuptake inhibitor antidepressants in hot flash patients under androgen-deprivation therapy for prostate cancer. Prostate Cancer Prostatic Dis. 2006;9(3):275-278.

43. Nishiyama T, Kanazawa S, Watanabe R, Terunuma M, Takahashi K. Influence of hot flashes on quality of life in patients with prostate cancer treated with androgen deprivation therapy. Int J Urol. 2004;11(9):735-741.

44. Klotz LH, McNeill IY, Kebabdjian M, Zhang L, Chin JL; Canadian Urology Research Consortium. A phase 3, double-blind, randomised, parallel-group, placebo-controlled study of oral weekly alendronate for the prevention of androgen deprivation bone loss in nonmetastatic prostate cancer: the Cancer and Osteoporosis Research with Alendronate and Leuprolide (CORAL) study. Eur Urol. 2013;63(5):927-935.

45. Dearnaley DP, Sydes MR, Mason MD, et al; Mrc Pr05 Collaborators. A double-blind, placebo-controlled, randomized trial of oral sodium clodronate for metastatic prostate cancer (MRC PR05 Trial). $J$ Natl Cancer Inst. 2003;95(17):1300-1311.

46. Campbell SC, Bhoopalam N, Moritz TE, et al. The use of zoledronic acid in men receiving androgen deprivation therapy for prostate cancer with severe osteopenia or osteoporosis. Urology. 2010;75(5): $1138-1143$. 
47. Smith MR, Saad F, Egerdie B, et al. Effects of denosumab on bone mineral density in men receiving androgen deprivation therapy for prostate cancer. J Urol. 2009;182(6):2670-2675.

48. Smith MR, Morton RA, Barnette KG, et al. Toremifene to reduce fracture risk in men receiving androgen deprivation therapy for prostate cancer. J Urol. 2013;189(Suppl 1):S45-S50.

49. Smith MR, Fallon MA, Lee H, Finkelstein JS. Raloxifene to prevent gonadotropin-releasing hormone agonist-induced bone loss in men with prostate cancer: a randomized controlled trial. J Clin Endocrinol Metab. 2004;89(8):3841-3846.
50. Beer TM, Bergenstock M, Birt K, Higano CS. Darbepoetin alfa administered every 4 weeks for anemia in patients with advanced prostate cancer. Clin Genitourin Cancer. 2007;5(5):329-333.

\section{Publish your work in this journal}

Patient Related Outcome Measures is an international, peer-reviewed, open access journal focusing on treatment outcomes specifically relevant to patients. All aspects of patient care are addressed within the journal and practitioners from all disciplines are invited to submit their work as well as healthcare researchers and patient support groups.
The manuscript management system is completely online and includes a very quick and fair peer-review system. Visit http://www.dovepress. com/testimonials.php to read real quotes from published authors.

Submit your manuscript here: http://www.dovepress.com/patient-related-outcome-measures-journal 